\title{
Violencia política, derechos humanos y educación
}

\author{
Uiolência política, direitos humanos e educação
}

\section{Political violence, human rights and education}

\author{
Margarita Rosa Sgró ${ }^{1}$ \\ Facultad de Ciencias Humanas de la Universidad Nacional del Centro, \\ Coordinadora del Programa de Posgrado en Educación (Maestría y Doctorado); Profesora \\ Titular del Departamento de Educación
}

Resumen: El presente trabajo tiene como objetivo reflexionar sobre la responsabilidad, pero también sobre los condicionantes que los sistemas de educación tienen con respecto a la cultura política. Especialmente la cultura política contemporánea, cuya característica central parece ser el poner entre paréntesis principios elementales de las democracias. Trataremos de justificar la hipótesis que las críticas a la educación, sobre todo a la educación sistemática, derivan de exigirle a la escuela, en todos sus niveles, que forme un ciudadano capaz de pensar y actuar contra las corrientes culturales predominantes en la sociedad, sea en el campo de la formación de la autonomía del individuo, sea en la responsabilidad colectiva de participación social del ciudadano. Para delimitar el análisis nos vamos a centrar en la compleja relación entre educación, violencia política y derechos humanos.

Palabras clave: Violencia Política. Cultura política. Derechos Humanos. Educación. Democracia.

Resumo: $\bigcirc$ presente trabalho visa refletir sobre a responsabilidade, mas também acerca das condições que os sistemas de ensino têm em relação à cultura política. Trata-se sobretudo da cultura política contemporânea, cuja característica central parece ser a de subestimar os princípios elementares das democracias. Procuraremos justificar a hipótese de que a crítica à educação, especialmente a educação sistemática, deriva de exigir da escola, em todos os níveis, a formação de um cidadão capaz de pensar e agir contra as correntes culturais predominantes na sociedade, seja no campo da formação da autonomia do indivíduo, seja na responsabilidade coletiva da participação

Doctora en Educación; Licenciada en Ciencias de la Educación. 
social do cidadão. Para delimitar a análise, vamos nos concentrar na complexa relação entre educação, violência política e direitos humanos.

Palavras-chave: Violência política. Cultura política. Direitos Humanos. Educação. Democracia.

Abstract: This article intends to reflect not only on the responsibility but also on the constraints that educational systems have as regards political culture. Especially contemporary political culture, whose main characteristic seems to be not to consider the basic principles of democracies. We will try to justify the hypothesis that critiques to education, especially to formal education, demand from school. That is, to educate a citizen able to think and act against the predominant cultural currents in society either in the area of the formation of the individual autonomy or in the citizen's collective responsibility of social participation. To define this analysis we are going to focus on the complex relationship between education, political violence and human rights.

Keywords: Political Violence. Political culture. Human Rigths. Education. Democracy.

\title{
1 INTRODUCCIÓN
}

\begin{abstract}
Desde la responsabilidad que alberga el presente sobre las verdades de (ese) pasado y los intereses políticos que hoy las debaten. No solo nos enfrentamos con el desafío de la crítica a lo acontecido en el campo de aquellas izquierdas, sino, desde hace años, con el debate sobre las políticas de las memorias de la violencia y la muerte. (CASULLO, 2007, p. 296).
\end{abstract}

La educación escolar es, en la actualidad, una práctica social muy criticada. Los cuestionamientos provienen de los sectores más diversos, las familias de los niños y jóvenes, los gobiernos neoliberales que buscan desfinanciarla y convertirla en un negocio rentable para el sector privado y buena parte de la sociedad que espera de la educación lo que aquella desalienta con sus prácticas cotidianas. Las críticas también surgen de los propios educadores y de los resultados de investigaciones educacionales que 
concluyen sobre su desactualización en contenidos, su excesiva formalización, su incapacidad de adaptación al mundo contemporáneo. Otras críticas provienen de considerarla una institución creada para garantizar el disciplinamiento de los cuerpos y ser finalmente un vehículo de represión de la individualidad. Esta breve enumeración no agota, de ningún modo, todo lo que se expresa sobre la escuela, sus déficits y su resistencia a la transformación.

La Modernidad, le asignó a la educación, sobre todo escolar, una tarea, la formación de las jóvenes generaciones para garantizar la innovación y la reproducción de la cultura, juntamente con la integración social. Se delegó en ella la formación de la subjetividad, la individualización y la socialización. Se le solicitó enriquecer la civilidad a través de la formación de ciudadanos. Se le pidió que fortalezca los lazos sociales mediante el ejercicio de la solidaridad y enseñe valores de cooperación. Todo esto mediante estrategias destinadas a la moralización, y transmisión de contenidos culturales seleccionados para tal fin.

Vaya esta pequeña introducción para justificar la siguiente hipótesis: las críticas a la educación, sobre todo a la educación sistemática, demandan de la escuela que forme un ciudadano capaz de pensar y actuar contra las corrientes culturales predominantes en la sociedad, sea en el campo de la formación de la autonomía del individuo, sea en la responsabilidad colectiva de participación social del ciudadano.

Los avances y retrocesos de la cultura política, las debilitadas instancias de diálogo y negociación, el ejercicio del poder no justificado a los ojos de todos los involucrados en una situación dada, develan los déficits de formación de la ciudadanía, pero revelan también las coordenadas en las que se mueve una cultura política degradada, que ha roto con el principio de igualdad de oportunidades y un criterio defendible de justicia social. De allí, que lo político se exprese cada vez más frecuentemente de modo violento, es decir, no justificado frente a la mirada de todos los involucrados; sin respeto por los más elementales derechos humanos, que tanto costó colocar como tema en la arena pública. Sin ninguna duda, es este un tema educacional impostergable, no solo para los educadores y pedagogos, sino también para las fuerzas democráticas de nuestras sociedades, que frecuentemente coinciden con las concepciones neoliberales y neoconservadoras en los cuestionamientos 
a la educación pública. Sin distinguir que la acción educacional es, antes que un cúmulo de instrumentos de transmisión de saberes, una práctica vital para el ejercicio de la democracia. Su naturaleza ético-política la coloca en esa relación inescindible.

Si llegamos a plantear como hipótesis, el divorcio entre las exigencias depositadas en la escuela y la marcha cultural de las sociedades en las que se instala, es porque leemos la misión política de la educación como misión de emancipación social, en sociedades neocoloniales y altamente inestables como las Latinoamericanas. Las fuentes teóricas que nos han llevado por este camino son el Pensamiento crítico latinoamericano, algunos de cuyos autores citaremos explícitamente en este texto, y la Teoría crítica de la sociedad, por sus dos tendencias claves: la crítica como sustento teórico y metodológico y la emancipación como punto de partida y de llegada del discurso teórico y político-pedagógico. Apostamos a un diálogo entre ambas vertientes que se ha desarrollado en las investigaciones de los últimos años, por lo que sustentan nuestras investigaciones presentes.

Cabe aclarar que en el desarrollo de nuestro pensamiento educacional, en el marco teórico y metodológico de referencia de nuestras investigaciones, la pedagogía se separa claramente de la didáctica para estrecharse con la política, tal como fue concebida históricamente hasta el advenimiento de la hegemonía tecnocrática en el campo educacional.

\section{A MODO DE DIAGNÓSTICO GENERAL}

Los pueblos latinoamericanos, compartimos, por la simultaneidad de los procesos, tiempos de dictaduras y democracias que se sucedieron casi sin excepción. A lo largo del siglo XX fuimos testigos de dictaduras militares y períodos de gobiernos democráticos jaqueados por los poderes fácticos, cuyo brazo armado, las Fuerzas Armadas de cada país fueron las encargadas de ejecutar las políticas de saqueo y extranjerización de la economía, de reducción de derechos, de aumento de la desigualdad y de otras formas de 
injusticia social, como el desprecio hacia los que menos tienen o la invisibilidad de lo diverso.

Asentados sobre una estrategia de terror, cárcel, tortura y "desaparición forzada" de personas, la dictadura del año 1976 en Argentina, fue el brazo armado del poder económico. La garantía de inmovilizar a una sociedad que asistiría, sin reflejos ni organización suficientes, a la implantación de un proyecto económico oligárquico, cuya pretensión fue sepultar cualquier indicio de gobierno popular que desde las izquierdas no ortodoxas y el Peronismo revolucionario pudiera gestarse.

Los militares contaron con el silencio de la jerarquía de la Iglesia Católica, lo que les permitió secuestrar, torturar y desaparecer a militantes políticos, militantes sociales, sindicalistas, trabajadores y estudiantes, con una planificación que abarcó varios países. Alcanzados por planes coordinados de represión Argentina, Brasil, Uruguay, Paraguay y Chile establecieron, conjuntamente, el "Terrorismo de Estado" como estrategia política y de gobierno.

Los efectos económicos y sobre la vida colectiva se extendieron por muchos años y aun se sienten, cuando la política, que teóricamente debe destinarse al bien común, se va reduciendo a tácticas que mantienen los privilegios de las minorías. El "Terrorismo de Estado" dejó también como consecuencia, democracias formalizadas que habilitan proyectos "políticos" cuya fuerza está en el marketing y en estrategias de comunicación destinadas a vaciar de contenido las orientaciones de la vida social.

En Argentina, al debate público-político le falta una generación que fue diezmada entre los años 1976 y 1979, con el saldo de 30.000 desaparecidos y otros miles de presos y torturados. El retorno de Gobiernos neoliberales, en la actualidad, mantiene la continuidad de una economía favorable a los privilegiados y una cultura política basada en el desprecio por la historia común y por las tradiciones compartidas. Un criterio de utilidad mercantil se instala en las culturas contemporáneas vaciando el contenido de lo colectivo. La política se judicializa y de este modo ya no es potestad de la ciudadanía, sino de un grupo de técnicos a los que nadie eligió y que sin embargo, deciden sobre cuestiones altamente sensibles para el presente y el futuro de 
millones de personas. En solo cuarenta o cincuenta años de historia reciente, el retroceso de la vida política, el empobrecimiento de las clases bajas y medias bajas y la fragmentación social crecieron exponencialmente, a las Dictaduras sobrevinieron períodos de democracias neoliberales, cuyas consecuencias, social y económicamente hablando, no fueron menos lesivas.

Años en que la prédica contra el Estado, la solidaridad social, la responsabilidad ciudadana, fueron reemplazadas en el discurso público por la eficiencia, el lucro, y el éxito individual. Lo que hoy se entiende como emprendedurismo no es más que la consolidación de una ideología que impulsa a salvarse solo. Estos procesos se consolidaron en parte por los desengaños de las revoluciones fracasadas, por no haber cumplido las promesas que en ellas se depositaron y también por la "La categórica y afiatada embestida cultural de las derechas capitalistas [...] la propuesta de todo el poder al mercado [...] el conservadurismo de los mundos intelectuales en apoyo a esta nueva metafísica publicitaria de lo 'inexorable'." (CASULLO, 2007, p. 15).

Sin querer ampliar los antecedentes y causas de los procesos histórico-políticos brevemente descriptos, debemos reafirmar que el tiempo contemporáneo está signado por la violencia política, la desigualdad y la injusticia social. La falta de respecto a los derechos humanos más elementales, es parte de la vida cotidiana, somos testigos de catástrofes a las que nos acostumbramos, casi sin percibirlo. Violencia explícita de las Fuerzas de Seguridad contra los jóvenes más pobres, los extranjeros, las mujeres, etc.

Es evidente, que la concentración de la riqueza en pocas manos y la consecuente desigualdad extrema, las formas de desprecio y exclusión, predominan como formas de relación social en las sociedades contemporáneas.

En un texto denominado La rebelión de los límites, la crisis de la deuda, el vaciamiento de la democracia y el genocidio económico-social Franz Hinkelammert, teólogo alemán exponente de la Teología de la liberación, remite a un texto bíblico al afirmar que:

El poder económico deja morir, el poder político ejecuta. Ambos matan aunque con medios diferentes. Por eso, el poder político tiene que justificar el matar mientras el po- 
der económico tiene que justificar por qué deja morir y no interviene en el genocidio dictado por el mercado. Sea cual sea la justificación ambos son asesinos. (HINKELAMMERT, 2014, p. 218).

Estos fenómenos no son nuevos, la historia de occidente en los últimos siglos da cuenta de ello con sobrados ejemplos. Sin embargo, la novedad de nuestro tiempo es que esa cultura del individualismo, el éxito personal, el desinterés por los "otros" y el ambiente, parece ganar terreno en la opinión pública; desmembrando lo poco que queda de lazos sociales más o menos estables y formas de civilidad basadas en principios de libertad e igualdad, más o menos generalizables. La continuidad de los proyectos económicos de las dictaduras, estuvo asegurada en democracia por el neoliberalismo, éste ya no requiere del terror masivo e indiscriminado, antes bien, se asienta en un terreno de aspiraciones al consumo, y de una imaginaria pertenencia a las clases altas, que la publicidad, y los modelos dominantes en los medios de comunicación, inculcan sin que estemos demasiado preparados para una "recepción crítica".

Diagnósticos complejos de un tiempo, en el que las orientaciones colectivas de la vida social cambian aceleradamente. Un tiempo, que al decir de Nicolás Casullo, sociólogo argentino fallecido en 2008, se resigna con la imposibilidad de la idea de "revolución", que dejó un hueco en occidente, cubierto frecuentemente con la declaración de muerte de los relatos emancipatorios, y el consecuente debilitamiento de la crítica. "En esta desertificación, esta desustancialización o formalismo técnico-gestionante de lo político vía perdida de un telos conductor, el fin de la (noción) de revolución resultaría una estación terminal de la idea de conquista de una historia del bien." (CASULLO, 2007, p. 124).

La clausura del debate social crítico, los esfuerzos de deshistorizar las diferentes perspectivas sociales, el afán por pensar siempre desde y para el tiempo presente, la ruptura de todo vínculo con el pasado teórico, el presente perpetuo, caracterizan el escenario en el que es posible que lo político en tanto, orientación valorativa de la vida social y comunitaria, sea reemplazado por un "formalismo técnico" cuyo objetivo es gestionar lo existente. Sin perspectiva 
de emancipación social, bien común y solidaridad social, reconocimiento, respeto por la diversidad e inclusión social, lo político solo puede tramitarse mediante la violencia del desprecio o la exclusión social y cultural. Como contrapartida el discurso meramente ideológico se muestra impotente, recurriendo a un pensamiento utópico que no tiene chances de convertirse en práctica social. El discurso puramente ideológico, típico de las izquierdas tradicionales rehúye, en el análisis del tiempo presente, la identificación de los indicios de emancipación, que efectivamente permitan una práctica política transformadora de la realidad social.

En el marco de concepciones tecnocráticas de pensamiento político, también de una pedagogía predominantemente instrumental, las demandas de una educación crítica para la formación de ciudadanía democrática son, sino insustentables muy difíciles de sustentar. Para que una educación sea capaz de innovar las prácticas antidemocráticas o poco democráticas, o contrarrestar el desprecio por los otros, sea capaz de luchar contra estilos discriminatorios y sexistas de comportamiento social, se hace imprescindible recuperar en el discurso político y en las orientaciones pedagógicas, la relación entre crítica y emancipación de modo que la crítica gane en perspectiva propositiva, no es solo pensar el presente, es también pensar el futuro, indagando en el presente con los ojos puestos en las perspectivas contenidas en él pero aún no desenvueltas.

Pero la cultura política dominada por formas de desprecio hacia los diferentes, hacia los pobres, hacia los más débiles de la vida social, cuenta con actores que nunca como ahora tuvieron la fuerza inusitada de interferir en la experiencia vivida de las personas, los medios de comunicación, la "cultura digital" y otras formas, mucho más sofisticadas, de direccionar la conducta de los ciudadanos y especialmente los electores, también redefinen el papel formador de la educación, tal como la hemos entendido hasta nuestros días. 


\section{MEDIOS DE COMUNICACIÓN, CULTURA DIGITAL Y EDUCACIÓN}

La cultura digital aporta rapidez, facilidades de comunicación inmediata y democratización de la información, a la par que profundiza la fragmentación social mediante la disparidad de acceso a contenidos de las ciencias y de la cultura, así como diferencias cada vez más importantes en las diversas formas de procesamiento de esos contenidos.

La multiplicidad de fuentes de información, se paga con una cuota de superficialidad e inmediatez en la que cada nuevo dato es sustituido por otro con el que, muy probablemente, no guarda ninguna relación.

La multiplicación de las posibilidades de comunicación mediante redes sociales, transforma las características de la comunicación sin, por ello, reemplazar la calidad de las relaciones cara a cara. Con estos fenómenos nuevos se ve obligada a convivir la educación escolar que a lo largo de su existencia tuvo el monopolio de la transmisión de saberes seleccionados y sistematizados. Seleccionados en función de fines y objetivos, frecuentemente excluyentes y discriminatorios con respecto a las culturas originarias o a la diversidad sexual, religiosa, etc.

No son pocas las voces que expresan que el déficit más importante de la educación escolar es la incapacidad de ampliar sus marcos culturales referenciales para incluir, junto con el reconocimiento de la multiculturalidad, la consideración del "otro" como interlocutor en un proceso dialógico en el que todos estén dispuestos a mudar, enriqueciendo su cultura de base. Sin embargo, ese déficit, no lo subsana la cultura digital.

En los años '90, circulaba en el discurso pedagógico, una cierta fascinación por las nuevas tecnologías de la información y la comunicación puestas al servicio de la educación, sobre todo de la "educación a distancia", hasta se llegó a hablar de que el aula virtual reemplazaría la presencialidad. En un texto del año 2015, reflexionábamos sobre este tema diciendo lo siguiente: 
constantes y nos obliga a responder a veces en forma deliberada, otras veces de manera inconsciente pero siempre rápido, no hay mucho tiempo para pensar respuestas, tomar partido, reflexionar. No obstante, situarnos en ese cúmulo movedizo de información requiere de criterios de selección, clasificación y comprensión que demandan una "formación" previa que no puede reducirse simplemente a la utilidad. En otras palabras no es suficiente dominar destrezas técnicas para interpretar, para pensar, para entender. (SGRO, 2015, p. 86).

No obstante, aun cuando no podemos abstraernos de la diseminación de la cultura digital, continúa abierta la cuestión fundamental de la educación: “[...] a perplexidade pedagógica gerada pela sociedade digital pode ser enfrentada [...] na medida em que, enquanto educadores, nós formos capazes de preservar aspectos do sentido iluminista da formação humana, atualizandoos de acordo com as exigências dos novos tempos." (DALBOSCO, 2015, p. 25).

La enorme cobertura poblacional de los medios masivos de comunicación, sostiene la cultura degradada del entretenimiento, la exposición de vidas privadas, la confusión entre ficción y realidad, la incitación al consumo y la creación de mundos ficticios que completan un escenario social hegemónico, adverso a la cultura escolar.

En un sentido amplio, es responsabilidad de los medios masivos de comunicación concentrados en pocas manos, la degradación de la cultura política democrática, que se completa con la impotencia de las instituciones de la vida civil como los partidos políticos, las asociaciones de la sociedad civil, para contrarrestar los efectos de la mercantilización de la vida, la creación de ideologías discriminatorias, el odio a los más desprotegidos de la escala social, la violencia cotidiana multiplicada en cientos de imágenes.

Las relaciones cara a cara, el diálogo que permite exponer la experiencia propia, al tiempo que facilita la reflexión sobre la misma, van cediendo su lugar a las redes sociales y a un individualismo nuevo, el de mundos propios o mundos divididos por intereses grupales a los que, cada vez más direccionadamente, se dirige la publicidad, tanto sea la destinada al consumo, la más tradicional, como así también la destinada a la creación 
de percepciones colectivas, de conciencias cosificadas y encerradas en sus intereses particulares.

\begin{abstract}
El Capital es el soberano que tiene que ser confirmado por la soberanía popular. [...] Ese es el vaciamiento de la democracia, [...] El pueblo renuncia a su soberanía y la entrega al poder económico que se hace presente como Capital. Los métodos para lograrlo son muchos. Solo queremos mencionar dos, que tienen un carácter central: la creación de la opinión pública en el sentido de una opinión publicada, y la amplia determinación de la política por el financiamiento de las elecciones.

El dominio sobre los medios de comunicación hoy está casi por completo en las manos de sociedades de capital, que son sus propietarias. Los medios de comunicación se basan en la libertad de prensa que es la libertad de los propietarios de los medios de comunicación. (HINKELAMMERT, 2014, p. 214-215).
\end{abstract}

Los partidos políticos, las asociaciones civiles y la propia escuela también son parte de una sociedad atravesada por la mercantilización y la dominación político ideológica, pero cuentan con una importante diferencia, son instituciones en las que las relaciones cara a cara, todavía son insustituibles, y por ello, la cultura vivida de cada sujeto se vuelve el punto de partida pero también se enriquece en el proceso de diálogo experiencial que se sostiene con "otros". La teoría de educación se ocupó del valor de la experiencia en autores cuyos marcos histórico-políticos fueron muy disimiles, Theodor Adorno fue uno de ellos, en él pueden encontrarse ricas reflexiones sobre el tema, vinculadas justamente a una educación contra la barbarie.

\footnotetext{
Afectado definitivamente por el tema del Nazismo, el filósofo frankfurtiano entiende que es la primacía de una racionalidad utilitarista y calculadora la que ha llevado a la humanidad a una carrera ciega hacia la autodestrucción. [...] Pero un clima espiritual, social y cultural capaz de crear condiciones para una vida emancipada no depende de la voluntad de los individuos separadamente, sino de percibir a la democracia como la única forma de vida en la que los sujetos podemos ser autónomos y la sociedad emancipada. (SGRO, 2017, p. 192).
} 
No obstante, la sociedad, las familias en sus variadas versiones, los adultos, demandamos a la escuela una tarea ciclópea la de la formación moral y cultural contraria a las orientaciones dominantes. Esa exigencia nos parece completamente legítima, siempre que reconozcamos que esa es la dirección que debe seguir cualquier sociedad que quiera garantizar una vida digna para todos. Nótese que no estamos hablando de homogeniedad cultural ni ideológica, sino de un acuerdo mínimo que haga que los ciudadanos no dejen en manos ajenas, en este caso, en las manos del capital concentrado, sus expectativas de vida.

Pero el avance del neoconservadurismo, pone en duda pactos que las democracias latinoamericanas parecían asegurar. La llegada al poder de gobiernos neoliberales, y neoconservadores, fragiliza aún más los ya de por sí debilitados principios democráticos jaqueados por poderes transnacionales y una vocación neocolonial, alentada por buena parte de los poderes fácticos locales.

En ese contexto adverso, parece más adecuado sincerar las demandas en un gran debate que admita, como punto de partida, que la educación es un hecho político y que como tal puede acompañar procesos de transformación social, impulsarlos, cuestionarlos o acelerarlos; o, puede simplemente reproducir modelos de gerenciamiento social, meritocráticos, en sociedades que por momentos, parecen estar muy a gusto con modelos de exclusión social.

Ese debate se está produciendo hace ya varios años y abarca los déficits de la pedagogía moderno-iluminista y las críticas provenientes de las pedagogías críticas latinoamericanas, en todas sus versiones. Mientras las derechas apuntan su crítica al derrumbe de lo público y con ello de la educación pública, el pensamiento crítico y emancipatorio debe apuntar a repensar la escuela pública de calidad para todos. En ese punto, la educación debe ocuparse de la cultura política y especialmente de la violencia política que radica fundamentalmente en el desconocimiento de derechos por parte de los poderosos, hoy, especialmente de derechos sociales. Los dos modelos en pugna que se presentan en la contemporaneidad de muchos países latinoamericanos podrían claramente definirse como proyectos de inclusión o 
exclusión social. Ese conflicto que está en la base de las sociedades de nuestro tiempo define el dilema fundamental.

Sin embargo, la potencia de las relaciones cara a cara, el diálogo sobre la experiencia vivida, las prácticas solidarias y de responsabilidad social que se impulsen en las escuelas son, sin duda formas de una cultura política basada en el respeto por la diversidad. Capaz de mostrar los déficits de una forma excluyente de la política que declama la igualdad mientras empobrece y discrimina, y declama justicia cerrando cada vez más los espacios de autonomía y decisión de la ciudadanía.

\section{LA SOCIEDAD LE EXIGE A LA ESCUELA}

La noción "crisis de la educación" es un concepto que los pedagogos habitualmente expresamos. Un señalamiento a la educación escolar en sus diferentes niveles y modalidades, destinado a mostrar las deficiencias de una institución creada para distribuir la cultura letrada, garantizando la inclusión de las jóvenes generaciones y simultáneamente la supervivencia de la sociedad y la integración de la misma. A grandes rasgos los sistemas educacionales nacieron como instituciones capaces de consolidar los Estados Nacionales. Garantizar la igualdad de oportunidades educacionales era una forma de garantizar igualdad de oportunidades sociales, acompañadas con un conjunto de otras políticas sociales destinadas a la inclusión diferenciada pero inclusión al fin. En este sentido, fue pensada la relación entre educación y democracia durante los siglos XIX y XX.

Principios de igualdad de oportunidades y libertades cívicas, guiaban la construcción de un currículum con "contenidos", saberes de carácter científico y cultural, saberes cívicos y respeto a las normas sociales. Simultáneamente, el tiempo escolar es, aún el de una pequeña comunidad con reglas establecidas que, idealmente, reproducen las reglas de la sociedad. Horas destinadas a la producción, a la convivencia, al aprendizaje y más recientemente a gestionar la disciplina interna de las instituciones para promover la participación de los 
estudiantes en la gestión general de la institución. Bajo supervisión de los adultos que, en teoría, no deben ceder su lugar de adultos, guías, u orientadores.

Es este modelo escolar, que funcionó más o menos ajustadamente durante mucho tiempo, el que está en crisis. De este modo, las críticas que contemporáneamente acaban en denunciar la crisis de la educación, señalan con una cuota de razón, que todo este andamiaje ya no puede ser sostenido y la educación escolar actúa como una caricatura, que no abandona las grandes proclamas en las que ya nadie cree.

Concediendo una cierta cuota de verdad a estos análisis parciales, es imprescindible analizar algunas líneas de resolución de estos problemas, o lo que es lo mismo orientar la práctica educacional en una nueva dirección.

¿Pero cuál sería esa dirección? En el intento de responder la pregunta precedente, o más frecuentemente, en el abandono de ese intento, está presa la teoría de educación contemporánea, por no trazar con claridad las tensiones evidentes entre demandas planteadas a la escuela y demandas sociales de adaptación al mercado de trabajo y a formas de participación social tuteladas.

Los teóricos que adscribimos a concepciones críticas, le exigimos a la escuela que sea contrahegemónica, que forme sujetos solidarios y críticos, democráticos y responsables de sí mismos, cuando las tendencias culturales hegemónicas de la sociedad contemporánea van en sentido contrario. En cierto modo, los teóricos críticos, defendemos en el plano político una educación que consideramos indefendible desde un punto de vista pedagógico, como dijera Paulo Freire en una conferencia en Buenos Aires en 1993, de la que no conseguí registro alguno, solo los educadores progresistas corremos el riesgo de ser incoherentes.

Críticos y no críticos pecamos por la misma deficiencia, pensar la educación como un hecho o una práctica desgajada del contexto social, a la que se puede analizar como una variable independiente.

Hay que reconocer que la educación escolar pública y gratuita se encuentra, frente al avance de la cultura digital, de los medios masivos y su incidencia en la cultura, relativamente desprotegida. La proclama que le otorgó legitimidad fue la igualdad de oportunidades, la universalidad del derecho a 
la educación, la inclusión social y la integración, tópicos que en el marco del avance neoliberal, se busca denodadamente clausurar. Por ello, a la pedagogía crítica debemos pedirle una reflexión que refuerce, justificadamente, el discurso de la politicidad de la educación, de su relación intrínseca con las formas democráticas de vida, con el cuidado de la vida y los Derechos Humanos, el primero de ellos, el derecho a una vida digna. Y para ello, la pedagogía debe, nuevamente, internarse en la tradición crítico-iluminista y latinoamericanista del discurso pedagógico emancipatorio.

\section{DERECHOS HUMANOS Y EDUCACIÓN}

Como hemos dicho anteriormente las dictaduras que gobernaron en diferentes países de nuestro continente, en la segunda mitad del siglo XX, fueron paulatinamente profundizando la violencia política mediante la tortura, el encierro, la desaparición forzada de personas y otras técnicas que sembraron el terror en toda la sociedad. Un terror indiscriminado y una desconfianza hacia los otros compatriotas o ciudadanos, desconfianza a los que reclaman justicia, a los que quieren saber y parar esos procesos, que acaban en la disolución social. Ese camino termina en el odio a todo tipo de acción colectiva, pública, tendiente al bien común o de perfil comunitario. Es decir, odio a lo político, a sus estructuras, y finalmente odio al Estado, entendido como la objetivación del mal, acusado de corrupción, desidia, ineficiencia, etc.

Esos procesos del campo social y cultural no pudieron revertirse democráticamente, aun cuando en muchos países latinoamericanos el siglo XXI comenzó con gobiernos de signo popular o progresista, que llevaron adelante políticas de redistribución de renta, protección al trabajador y fomento de la industria. Políticas tendientes a la constitución de la unidad latinoamericana, mediante estrategias de mercado común e iniciativas interesadas en consolidar un bloque de países Sudamericanos capaces de disputar poder y enfrentar unidos las decisiones adversas, que frecuentemente las potencias europeas y Estados Unidos de América propician para defender sus propios intereses. 
Las políticas de reparación social y cultural, abarcaron la fundación de nuevas universidades, nuevas escuelas, becas para garantizar la escolaridad, ampliación de los años de obligatoriedad escolar, distribución de libros y computadoras para los niños y sus docentes. A pesar de todas esas políticas reparadoras, la restauración conservadora parece hegemonizarse en nuestros países, dando paso a formas de democracia reducida, dependiente, neocolonial. El Estado de Derecho entró en crisis y la judicialización de la política la aleja de la ciudadanía, ampliando la desconfianza de las masas populares hacia formas de organización colectiva y participación, que son las únicas capaces de detener el avance contra los derechos adquiridos y la transferencia de renta hacia las clases dominantes.

Durante la primera década y media del presente siglo las políticas de Memoria, verdad y justicia se convirtieron en Políticas de Estado, institucionalizando la lucha que venían realizando los movimientos de Derechos Humanos.

La particularidad se dio porque en Argentina se produjo, paralelamente a procesos de violencia extrema generados desde el Estado Terrorista, como los de última dictadura cívico-militar-eclesial; un movimiento de resistencia, único en América Latina, que es el movimiento de Derechos Humanos, encabezado por las "Madres de Plaza de Mayo" y las "Abuelas de Plaza de Mayo" que buscan a sus nietos robados y dados en adopción, después de haber nacido durante el cautiverio de sus madres. También existe el "Movimiento de familiares de detenidos y desaparecidos", la "Asamblea permanente por los Derechos Humanos", "Hijos de detenidos desaparecidos", y más recientemente los hijos e hijas de los policías y militares responsables de la tortura o responsables de Centros Clandestinos de Detención; se reunieron en una asociación para manifestar el desprecio por la acción de sus padres durante la dictadura.

En los primeros años del siglo XXI lo que eran movimientos de resistencia de Derechos humanos fueron convertidos en políticas del Estado Nacional, en los años de Gobierno del Frente para la Victoria de los presidentes Néstor Kirchner y Cristina Fernández de Kirchner, los derechos humanos se incorporan junto a otras políticas de reparación social a una experiencia 
de políticas públicas que buscaban restablecer "derechos", mediante una redistribución progresiva de la riqueza y el reconocimiento de derechos a las minorías sexuales, por ejemplo, que consiguieron a partir de una lucha de muchos años, la sanción de la Ley de Matrimonio Igualitario para parejas del mismo sexo. En el mismo sentido, la lucha de los diversos feminismos consiguió recientemente un avance fundamental para sancionar una Ley de Interrupción Voluntaria del Embarazo (IVE) que tuvo media sanción en la Cámara de Diputados y se encamina a la Cámara de Senadores. La presión ejercida por un movimiento de miles y miles de personas en las calles generó un avance fenomenal con respecto al tema, así como el respeto hacia las mujeres y su derecho a la igualdad sexual, económica y política. Los Movimientos sociales, los Feminismos, los Movimientos que reivindican Tierra, Techo y Trabajo, así como el Movimiento de Trabajadores Desocupados o los de la "economía popular", se orientan en el mismo sentido de hacer oír sus reclamos mediante una presencia constante en las calles, que sensibilizan y educan a una sociedad, que ya no puede fingir desconocimiento frente a los reclamos de los más desprotegidos.

En los primeros días de gobierno del Presidente Néstor Kirchner entraron por primera vez a la casa de Gobierno, (Casa Rosada) las Madres y las Abuelas de Plaza de Mayo y otros organizamos de Derechos Humanos, que a pesar de que habían pasado -en el año 2003- más de veinte años de democracia, nunca habían sido interlocutores de ningún gobierno. Con los dos Presidentes Kirchner empezaron a ocupar un lugar preferencial siendo la contraparte de un diálogo entre Estado y Sociedad Civil, que llevó a su punto más alto una relación vital para las políticas de Memoria, Verdad y Justicia. Se cerraba un ciclo de desencuentros en las lecturas del pasado que equiparaban la violencia planificada del Terrorismo de Estado con la violencia de los movimientos guerrilleros, revolucionarios extinguidos mucho antes del fin del terror. En 20 años de gobiernos democráticos nunca habían sido recibidos oficialmente. Se instauró el día 24 de marzo como día Nacional de la Memoria, conmemorando el inicio de la última dictadura, autodenominada "Proceso de Reorganización Nacional". Un período trágico de la historia que se extendería por casi ocho años. En ese tiempo los argentinos conocimos el 
horror de la violencia política estatal, que había empezado muchos años antes contra población civil indefensa.

En el mes de julio de 1955 aviones de las Fuerzas Armadas, bombardearon Plaza de Mayo a las 12 horas del mediodía, cuando los niños salían de las escuelas y la Plaza estaba colmada de personas que la transitaban. La crónica histórica registra 300 muertos declarados y miles de heridos. Poco después, en el mes de septiembre de ese mismo año, cae por un Golpe de Estado cívico-militar, el gobierno del General Perón y se afianza la inestabilidad política en la alternancia de gobiernos democráticos y períodos de dictadura. Así llegamos a la última dictadura finalizada en el año 1983 después de una guerra perdida contra Inglaterra por el territorio de las Islas Malvinas.

En esos ocho años la andanada contra el campo de la cultura democrática y la educación pública fue enorme, miles de libros se quemaron públicamente, y se facilitó el desarrollo de la educación privada especialmente confesional católica. Quebraron editoriales, quemaron teatros y cines y las Universidades sufrieron el exilio de la mayoría de sus profesores más renombrados produciendo un proceso de vaciamiento que solo fue subsanado muchísimos años después.

En la actualidad los proyectos pedagógicos referidos a derechos humanos, que fueron casi exclusivamente alusivos a la última dictadura y al Terrorismo de Estado, incluyen también otras reivindicaciones sociales como por ejemplo, la defensa de los derechos de la mujer o de los pueblos originarios. En el año 2006, el tema derechos humanos se incluyó en los planes de estudio de todas las escuelas primarias, secundarias y de formación de profesores, garantizando el conocimiento del tema, dado que los alumnos que transitan hoy por las aulas nacieron cuando la democracia estaba instalada. A la educación argentina se le plantea este problema por primera vez, cómo hacer que la memoria sobreviva y acompañe los pedidos de justicia que aún no han sido atendidos. La mayoría de "Las madres de Plaza de Mayo" ya tienen noventa años, es imprescindible que los jóvenes las sustituyan en la lucha.

El lugar que los Derechos Humanos, entendidos como política de "Memoria, Verdad y Justicia" referidos a la última dictadura, ocupa en la 
educación sistemática, en todos sus niveles, es el punto de partida central para una educación contra la violencia política. En las escuelas públicas se dio el primer paso para institucionalizar, entre los más jóvenes, un debate sobre el Terrorismo de estado y la conculcación de libertades públicas. Del mismo modo, actualmente las luchas en derechos sociales y de géneros, integran las prácticas pedagógicas de una escuela pública atravesada por sus propias contradicciones y las de la sociedad. Disputas por los sentidos políticos del saber y los alcances, frecuentemente disminuidos de la vida democrática.

\section{A MODO DE CONCLUSIÓN: EXPERIENCIA FORMATIUA CONTRA LA BARBARIE}

Pretendimos mostrar que deliberadamente 0 no, los diferentes actores sociales le piden a la escuela que transmita una cultura que la sociedad claramente ha desestimado y reemplazado por variadas formas de violencia, que van desde el desprecio y la invisibilidad hasta formas de exterminio efectivas como las aplicadas por las Dictaduras o, más contemporáneamente por las fuerzas de seguridad especialmente entre los jóvenes de los sectores sociales más pobres. Pretendimos mostrar cuánto los medios de comunicación de masas inciden en la multiplicación de las variadas formas de violencia cotidiana y como incitan a ejercerlas. Pretendimos mostrar los claroscuros de la cultura digital sobre la educación formal. Pretendimos mostrar los peligros que acechan a la cultura democrática que la escuela debe enseñar, en sociedades inestables con riesgo permanente de autoritarismos diversos. Y sin embargo, la escuela tiene una potencia social que le ha permitido mantenerse a pesar de las críticas demoledoras a las que fue sometida en diferentes momentos históricos. Su potencia es también su mayor debilidad, el estar cruzada por los mismos conflictos de una sociedad desigual y compleja.

Pero la educación escolar tiene a su favor dos condiciones esenciales para enfrentar la diseminación de la cultura política violenta, así como formas diversas de desprecio y autoritarismo cotidianas. En primer lugar, 
las escuelas son todavía un espacio cuidado donde niños, jóvenes y adultos se encuentran regularmente cara a cara, y en el que, eventualmente, comparten sus experiencias de vida, comunicándolas para reflexionar sobre ellas en un espacio, que si la institución y los profesores propician, está exento de cualquier forma de coacción. Esto significa que en la escuela ningún tema debe estar vedado, y todo puede ser tratado sin la presión del juzgamiento social. Abrir un espacio para la escucha, para la reflexión conjunta, para el diálogo, es el camino para cumplir con la tarea formativa que es la más relevante desde el punto de vista de la vida social.

En segundo lugar, la escuela puede, sin la urgencia de lo irreversible, por ejemplo de la violencia, que fácilmente acontece en las calles, tramitar los conflictos sociales, asumiendo por encima de ellos, la lucha contra la barbarie a la que están expuestos sobre todo, los más débiles de nuestras sociedades.

En este sentido, tal como fue expresado anteriormente, es imperioso que la pedagogía retome el concepto de experiencia formativa optimizando en las relaciones cara a cara, en el diálogo con otros, una resignificación de la experiencia propia que nos conecte con el pasado histórico, con el pasado reciente y con la memoria colectiva. El Prof. Eldon Mühl se refiere a este tema diciendo que:

De acordo com Adorno (1996), sem a formação cultural e sem esforço reflexivo, a condição humana não se desenvolve e a vida se torna empobrecida. A experiência formativa da vida humana decorre do desenvolvimento de aptidões críticas e da compreensão dialética da realidade como un proceso contraditório, histórico e de totalidade. (MÜHL, 2017, p. 116).

Y agrega:

Adorno chama atenção para a perda da memoria coletiva em razão "da progressividade dos princípios burgueses", que desconsidera como necessária toda e qualquer experiência acumulada. Diante de tal circunstancia, lembranças, tradição e história são liquidadas em favor da racio- 
nalização progressiva dos procedimentos da produção industrial. (MÜHL, 2017, p. 117).

En un mundo donde el tiempo es lo más escaso, donde los jóvenes casi no tienen interlocutores adultos, donde la tecnología ocupa el lugar de los "otros", sigue siendo la escuela un espacio de relaciones humanas, un espacio donde se juntan diferentes perspectivas sociales, concepciones democráticas y no tanto, sin embargo, su especificidad está en ser todavía un espacio que merece ajustes permanentes que deben ser discutidos con vehemencia, sin olvidar, que en nuestros países, sigue siendo, para un sector creciente de la población más desprotegida socialmente, el único vehículo de acceso al saber y el único espacio de cuidado y protección social para millones de niños y jóvenes pobres a los que la violencia social o intrafamiliar, el delito y el narcotráfico esperan a la vuelta de la esquina. Son ellos sus primeras víctimas y es la escuela una de la instituciones encargada de protegerlos para, en la medida de lo posible, hacer que el mundo no sea tan injusto.

\section{REFERENCIAS}

CASULLO, N. Las Cuestiones. Buenos Aires: Fondo de Cultura Económica, 2007.

DALBOSCO, C. Formação humana na sociedade digital. In: MAIA, A.; SOARES ZUIN, A.; NABUCO LASTÓRIA, L. (Org.). Teoría crítica da cultura digital. Aspectos educacionais e psicológicos. São Paulo: Nankin-Capes, 2015. p. 11-26.

HINKELAMMERT, F. La rebelión de los límites, la crisis de la deuda, el vaciamiento de la democracia y el genocidio económico-social. In: CORAGGIO, J. LAVILLE, J. (Org.). Reinventar la izquierda en el siglo XXI. Hacia un diálogo Norte-Sur. Buenos Aires: CLACSO-Universidad Nacional de General Sarmiento, 2014.

MÜHL, E. Formação pedagógica: Educação, barbárie e experiência formativa. In: TREVISAN, A.; MEDIANEIRA TOMAZETTI, E.; DUTRA ROSSATTO, N. (Org.). Filosofia e educação. Ética, Biopolítica e Barbárie. Curitiba: Appris, 2017. p. 115-134. 
SGRÓ, M: Educación y democratización en la era de la cultura digital. In: MAIA, A.; SOARES ZUIN, A.; NABUCO LASTÓRIA, L. (Org.). Teoría crítica da cultura digital. Aspectos educacionais e psicológicos. São Paulo: Nankin-Capes, 2015. p. 81-92.

SGRÓ, M: Educación, Civilización y Barbarie. In: TREVISAN, A.; MEDIANEIRA TOMAZETTI, E.; DUTRA ROSSATTO, N. (Org.). Filosofia e educação. Ética, Biopolítica e Barbárie. Curitiba: Appris, 2017. 185-199.

Recibido en: 30 de abril de 2018 Acepto en: 02 de julio de 2018

Enderezo para correspondencia: Machado, 58, Tandil, Código Postal 7000, Provincia de Buenos Aires, Argentina; msgro@fch.unicen.edu.ar 